\title{
Measurements of Indoor Radon Levels and Gamma Dose Rates
}

\author{
Mirsina Mousavi Aghdam ${ }^{1}$, Stefania DaPelo ${ }^{2}$, Valentina Dentoni ${ }^{1}$, Viviana Fanti ${ }^{3}$, Alessandra \\ Bernardini $^{3}$, Paolo Randaccio ${ }^{4}$, Daniele Chiriu ${ }^{3}$ \\ ${ }^{1}$ Department of Civil and Environmental Engineering and Architecture \\ University of Cagliari \\ mirsina.aghdam@unica.it; vdentoni@unica.it \\ ${ }^{2}$ Department of Geology and Chemical Science \\ University of Cagliari, Cittadella Universitaria di Monserrato \\ sdapelo@unica.it, \\ ${ }^{3}$ Department of Physics, University of Cagliari \\ Cittadella Universitaria di Monserrato and Italian Institute for Nuclear Physics (INFN), Cagliari, Italy \\ viviana.fanti@ca.infn.it; alessandra.bernardini@dsf.unica.it ; daniele.chiriu@dsf.unica.it \\ ${ }^{4}$ Italian Institute for Nuclear Physics (INFN) \\ E-laboRad .Srl, Cagliari, Italy \\ paolo.randaccio@ca.infn.it
}

\begin{abstract}
In order to estimate indoor natural radioactivity levels, long and short-term radon tests and ambient gamma dose rate measurements have been performed in several environments of the Faculty of Engineering and in the student canteen of Cagliari University. The measured values were found below the recommended reference levels issued by Directive 2013/59/Euratom. Consistent information about building characteristics, living habits and exposure times were recorded, to be taken into account in the UNSCEAR model. The annual effective dose calculated for each room ranges from 0.004 to $0.628 \mathrm{mSvy}^{-1}$. The levels of radon concentration measured until now did not exceed the recommended threshold values; additional testing will be performed to ensure full compliance of indoor air quality requirements.
\end{abstract}

Keywords: Long term and short term radon test, Gamma dose rate, Public and work environment, University of Cagliari, Indoor air quality.

\section{Introduction}

Radon is a gaseous radioactive element which is a product of Uranium decay chain in nature. Inhalation of radon in indoor spaces contributes to about half of the annual dose of ionizing radiation [1]. Long-term exposure to radon and radioactive progenies can increase the risk of lung cancer [2]. The main source of radon gas is the uranium/radium component in the soil beneath the building's foundations. Other sources of radon include the construction material and the radon dissolved in water. The colorless radon gas can penetrate from soil to indoor spaces through cracks in building foundations, cavities, pipelines and through the sewage system. Metrological factors such as wind speed, indoor and outdoor temperature difference, barometric pressure, relative humidity can also influence indoor radon concentration [1 and references therein]. The concentration of radon indoor is in fact, a complex function of different parameters and it can change considerably even during a single day time interval. Therefore, the average value of long term tests (3-12 months) are normally used in radon assessment studies [2]. However, the results of short term tests can be used for initial screening or to perform follow-up test (i.e. a short term test using a Continuous Radon Monitor (CRM)) when the results of long term test exceed the limit values.

Directive 2013/59/Euratom recommends radon concentration level below $300 \mathrm{~Bq} / \mathrm{m}^{3}$ both for homes and workplaces [3]. In this research indoor radon activity concentration and indoor gamma dose rate were measured simultaneously and the effective dose due to exposure to radon and progenies was estimated.

\section{Materials and Methods}

The study was carried out at the Faculty of Engineering and at the student canteen of Cagliari University. According to the EPA radon testing guidelines, Solid State Nuclear Track Detectors (CR-39) were placed in different environments, mostly in the ground and underground levels (Figure 1). The ambient gamma dose rates were measured simultaneously in the center 
of the room at one meter above the ground, by using the handheld radiometer MKC-01CA1M. The gamma dose rate measurements were prolonged until the instrument statistic error decreased to 5 percent.

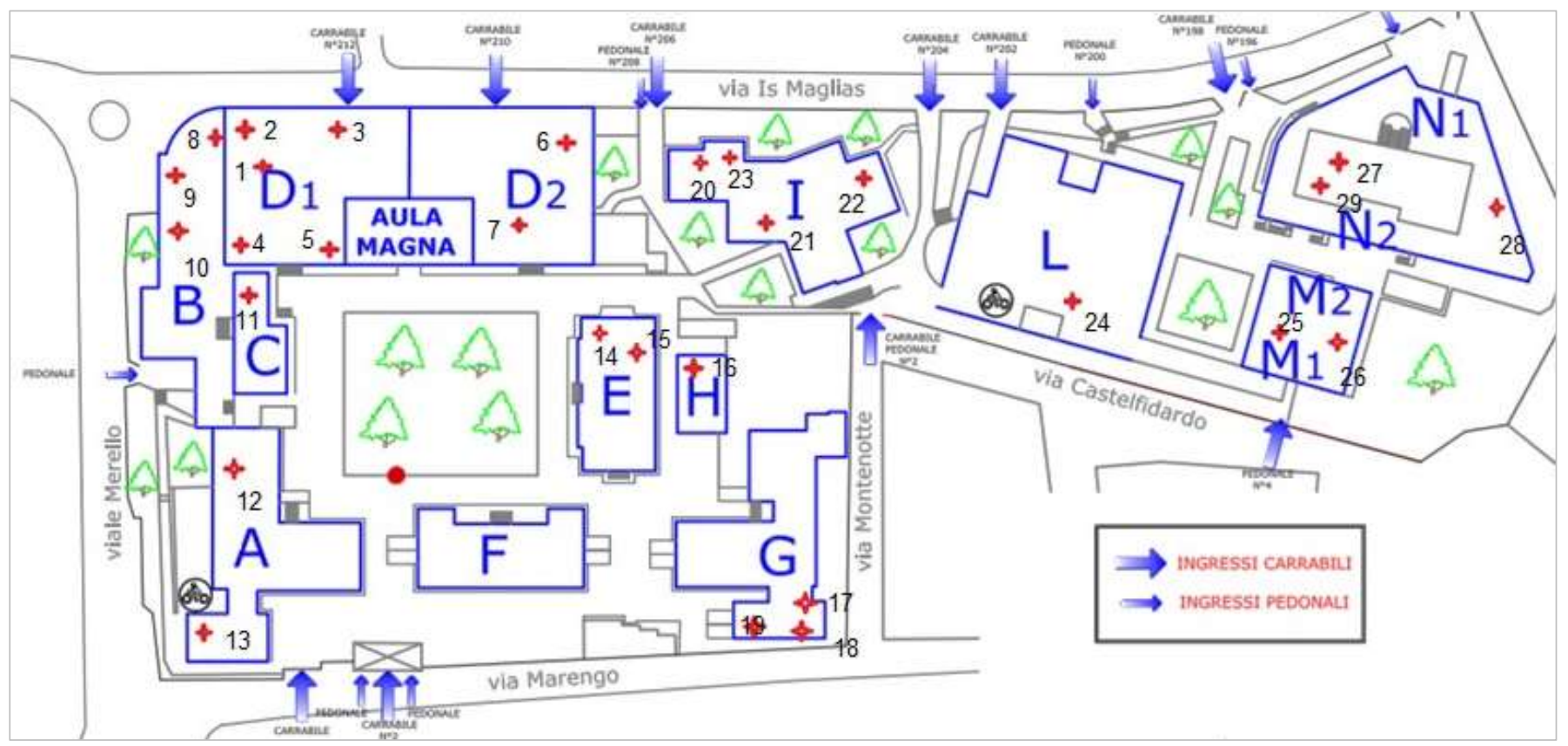

Fig. 1: Location of CR 39 detectors used for assessment of radon levels in different environments of engineering faculty, university of Cagliari, the base map extrapolated from UNICA portal (www.unica.it).

The exposure period of the CR-39 detectors was about 10 months, from March 2018 to January 2019. A questionnaire was prepared for each detector stating the testing information, type of building material, number of inhabitants, the time spent there and the ventilation rate of the room under exam. All the collected detectors were etched for four hours in a $6.25 \mathrm{~N}$ $\mathrm{NaOH}$ solution with a constant temperature of $90{ }^{\circ} \mathrm{C}$. The detectors were then removed and washed with distilled water. Using an optical microscope attached to a digital video camera, the alpha tracks were scanned. Based on the counted number of alpha tracks and using the calibration factor, the annual average concentration of radon and the standard deviation were calculated for each detector, as reported in Tab.1. According to the Canadian guide for radon measurements in public buildings, a follow-up test was carried out where the annual average concentration was higher than $200 \mathrm{~Bq} / \mathrm{m}^{3}$, by means of a RADEX MR107 radon gas detector (a CRM ion chamber). Finally, the Annual Effective Dose (AED) expressed in $\mathrm{mSvy}^{-1}$ was calculated according to the UNSCEAR model with Eq.1 [5]:

$$
A E D=\mathrm{CRn} \times \mathrm{F} \times \mathrm{D} \times \mathrm{u} \times \mathrm{t}
$$

where $\mathrm{CRn}$ is the radon concentration $\left(\mathrm{Bq} / \mathrm{m}^{3}\right), \mathrm{F}$ is the equilibrium factor between radon and progenies $(0.4$ for buildings), $\mathrm{D}$ is the dose conversion factor $\left(1.43 \mathrm{~Sv} / \mathrm{J} \mathrm{hm}^{-3}\right)$, $\mathrm{u}$ is the unit factor $\left(5.56 \times 10^{-9} \mathrm{~J} \cdot \mathrm{m}^{-3} / \mathrm{Bq} \cdot \mathrm{m}^{-3}\right)$ and $\mathrm{t}$ is the exposure time (hour) in a year. The total time spent in a week was recorded for each room, so the time periods in tab. 1 were multiplied by 52 and then used for calculation of AED.

\section{Results}

Indoor radon measurements were carried out in 32 different rooms, the geometric mean, the arithmetic mean, the minimum and maximum value of radon concentration were $57.60,74.37,12.00$ and $291.00\left(\mathrm{~Bq} / \mathrm{m}^{3}\right)$, respectively. The highest values were observed in the rooms located at the underground level and where air ventilation was poor. Fig. 2 shows the histogram of radon concentrations. As can be seen, all the measured values are below $300 \mathrm{~Bq} / \mathrm{m}^{3}$, which is the recommended level issued by the Euratom Directive. Just in one case, a storage room in the car parking, the value exceeded the level of $200 \mathrm{~Bq} / \mathrm{m}^{3}$ and thus the follow-up measurement was performed. Fig. 3 shows the results of the follow-up test carried out for about four days. The average value of radon concentration recorded during the follow-up test was below $200 \mathrm{~Bq} / \mathrm{m} 3$ (i.e.159 $\mathrm{Bq} / \mathrm{m}^{3}$ ), so that remediation action is not necessary [4]. Based on radon concentration and the time spent in a room, the annual 
effective dose due to exposure to radon and progenies were also calculated. As stated in Tab.1 all the calculated values of annual effective dose were below the ICRP recommended level of $1 \mathrm{mSv}$ per year. As observed in the case of the student canteen, the implementation of a proper ventilation system or even taking benefit of the natural air exchange by opening windows and door occasionally can avoid accumulation of radon.

Table 1: Details of measured indoor radon concentrations, gamma dose rates and calculated annual effective dose.

\begin{tabular}{|c|c|c|c|c|c|c|c|c|c|c|c|}
\hline 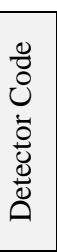 & 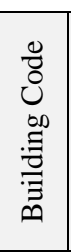 & 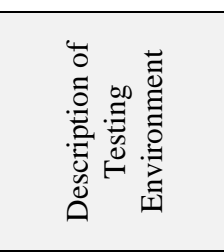 & 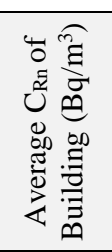 & 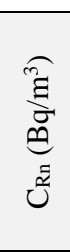 & 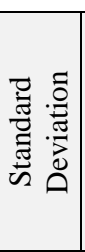 & 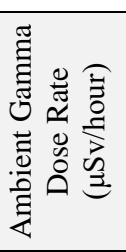 & 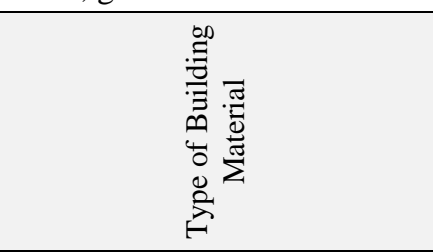 & 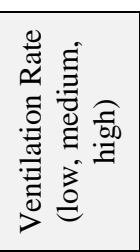 & $\frac{\dot{0}}{\overline{0}}$ & 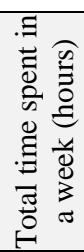 & 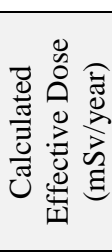 \\
\hline 1 & \multirow{7}{*}{$\mathrm{D}$} & Laboratory & \multirow{7}{*}{48.83} & 47 & \pm 15 & 0.17 & Painted Cement/ Ceramic Tiles & low & -1 & 15 & 0.117 \\
\hline 2 & & Workshop & & 27 & \pm 11 & 0.18 & Cement & High & -1 & 15 & 0.067 \\
\hline 3 & & Storage room & & 89 & \pm 35 & 0.21 & Painted Cement/Ceramic Tiles & low & -1 & 2 & 0.029 \\
\hline 4 & & Classroom & & 27 & \pm 8 & 0.21 & Painted cement /Brick/Linoleum & Medium & Ground & 8 & 0.036 \\
\hline 5 & & Study room & & 25 & \pm 12 & 0.19 & Painted cement /Brick/Linoleum & High & Ground & 20 & 0.083 \\
\hline 6 & & Laboratory & & 78 & \pm 20 & 0.31 & Painted Cement/Ceramic Tiles & Medium & -1 & 15 & 0.193 \\
\hline 7 & & Classroom & & NA & NA & 0.19 & Painted cement/Brick/Linoleum & Medium & Ground & NA & NA \\
\hline 8 & \multirow{3}{*}{ B } & $\begin{array}{c}\text { Copy } \\
\text { room/Corridor }\end{array}$ & \multirow{3}{*}{116.33} & 123 & \pm 20 & 0.28 & Bricks/Cement/Ceramic Tiles & Medium & -1 & 3 & 0.061 \\
\hline 9 & & Classroom & & 108 & \pm 28 & 0.25 & Bricks/Cement/Ceramic Tiles & Medium & -1 & 12 & 0.214 \\
\hline 10 & & Classroom & & 118 & \pm 37 & 0.27 & Bricks/Cement/Ceramic Tiles & Medium & -1 & 8 & 0.156 \\
\hline 11 & $\mathrm{C}$ & Classroom & NA & $\mathrm{NA}$ & NA & 0.21 & Painted Cement/ Ceramic Tiles & Medium & Ground & $\mathrm{NA}$ & NA \\
\hline 12 & \multirow{2}{*}{ A } & Storage room & \multirow{2}{*}{129.00} & 68 & \pm 20 & 0.20 & Cement/ Ceramic Tiles & low & Ground & 10 & 0.112 \\
\hline 13 & & Workshop & & 190 & \pm 27 & 0.19 & Cement & High & -1 & 20 & 0.628 \\
\hline 14 & \multirow{2}{*}{ E } & Corridor & \multirow{2}{*}{88.5} & 52 & \pm 18 & 0.24 & Painted cement/ Ceramic Tiles & Medium & Ground & 30 & 0.258 \\
\hline 15 & & Corridor & & 125 & \pm 31 & 0.19 & Painted cement/ Ceramic Tiles & low & Ground & 25 & 0.517 \\
\hline 16 & $\mathrm{H}$ & Secretary office & 42 & 42 & \pm 9 & 0.19 & Painted Cement/Ceramic Tiles & Medium & Ground & 40 & 0.278 \\
\hline 17 & \multirow{3}{*}{ G } & Corridor & \multirow{3}{*}{73.33} & 42 & \pm 16 & 0.20 & Ceramic Tiles & Medium & Ground & 16 & 0.111 \\
\hline 18 & & Corridor & & 121 & \pm 20 & 0.23 & Painted Cement/ Ceramic Tiles & Medium & -1 & 16 & 0.320 \\
\hline 19 & & Corridor & & 57 & \pm 19 & 0.15 & Painted Cement/ Ceramic Tiles & High & -1 & 16 & 0.151 \\
\hline 20 & \multirow{4}{*}{ I } & Classroom & \multirow{4}{*}{61} & 49 & \pm 10 & 0.24 & Painted cement/ Ceramic Tiles & Medium & Ground & 5 & 0.041 \\
\hline 21 & & Student office & & $\mathrm{NA}$ & NA & 0.18 & Painted cement/ Ceramic Tiles & low & Ground & 35 & NA \\
\hline 22 & & Classroom & & 73 & \pm 12 & 0.18 & Painted cement/ Ceramic Tiles & Medium & Ground & 8 & 0.097 \\
\hline 23 & & Classroom & & 61 & \pm 19 & 0.23 & Painted cement/ Ceramic Tiles & Medium & Ground & 6 & 0.061 \\
\hline 24 & $\mathrm{~L}$ & $\begin{array}{c}\text { Storage room in } \\
\text { car parking }\end{array}$ & 291 & 291 & \pm 62 & 0.27 & Cement & low & -1 & 1 & 0.048 \\
\hline 25 & \multirow{2}{*}{ M } & Storage room & \multirow{2}{*}{45} & NA & NA & 0.18 & Cement & low & Ground & NA & NA \\
\hline 26 & & Laboratory & & 45 & \pm 14 & 0.24 & Ceramic Tiles & High & Ground & 35 & 0.260 \\
\hline 27 & \multirow{3}{*}{$\mathrm{N}$} & Library & \multirow{3}{*}{39.67} & 51 & \pm 21 & 0.16 & Painted Cement/Linoleum & Medium & 1 & 25 & 0.211 \\
\hline 28 & & $\begin{array}{c}\text { Basement } \\
\text { storage }\end{array}$ & & 27 & \pm 9 & 0.11 & Cement & High & Ground & 1 & 0.004 \\
\hline 29 & & Computer room & & 41 & \pm 12 & 0.17 & Painted Cement/Linoleum & Medium & 1 & 20 & 0.136 \\
\hline 30 & \multirow{2}{*}{\multicolumn{2}{|c|}{ Mensa Via Trentino }} & \multirow{2}{*}{15.5} & 12 & \pm 7 & 0.24 & Painted Cement/ Ceramic Tiles & High & Ground & 12 & 0.024 \\
\hline 31 & & & & 19 & \pm 8 & 0.24 & Painted Cement/ Ceramic Tiles & High & Ground & 12 & 0.038 \\
\hline
\end{tabular}

NA: Not available because the detector was lost.

As mentioned before, gamma dose rate measurements were also carried out simultaneously. The lowest measured value was $0.11 \mu \mathrm{Sv} /$ hour and the highest $0.31 \mu \mathrm{Sv} /$ hour, while the arithmetic mean was found to be $0.21 \pm 0.04 \mu \mathrm{Sv} / \mathrm{hour}$ (see also 
Fig. 2 for the histogram of the measured gamma dose rates). The main source of indoor gamma radiation is the building materials and the materials lining the walls and floors of the rooms [6], however, in this research, no significant difference was found for different types of building material used in the tested environments.

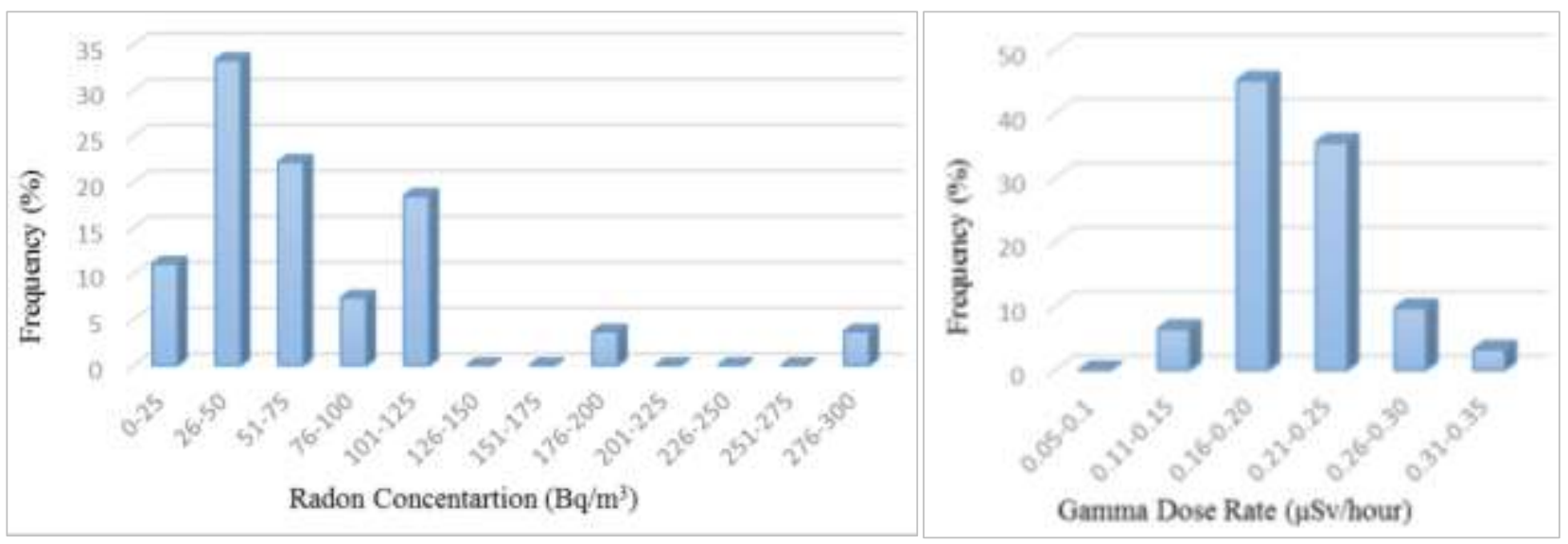

Fig. 2: Frequency distribution of measured indoor radon concentration and gamma dose rate.

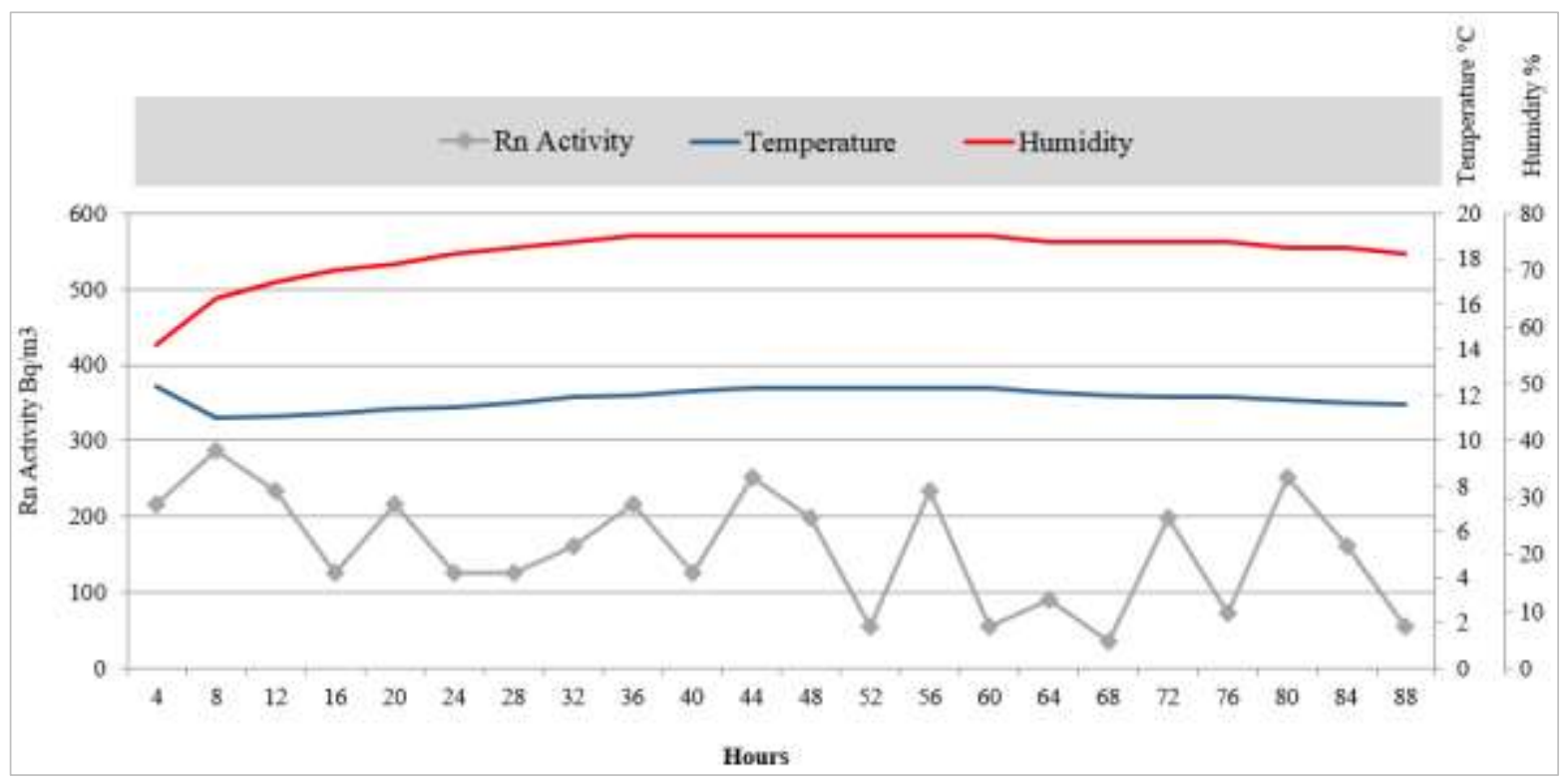

Fig. 3: Results of the follow-up radon test for the storage room in car parking.

\section{Conclusion}

Long-term exposure to radon can increase the risk of lung cancer. Therefore, public awareness about adverse health effects of radon should be increased and systematic measurement plans should be considered to identify environments where individuals are exposed to elevated radon levels. In this research, indoor radon concentrations and ambient gamma dose rates have been measured simultaneously based on the standard testing procedure. The most important point observed here was that using ventilation systems or even improving natural ventilation can effectively reduce radon levels. This can be an economic and a preliminary solution for increased radon levels, however, for the indoor spaces with significantly high concentration, the implementation of a remediation action is recommended.

\section{References}

[1] G. Ciotoli, M. Voltaggio, P. Tuccimei, M. Soligo, A. Pasculli, S.E. Beaubien, S. Bigi, "Geographically weighted regression and geostatistical techniques to construct the geogenic radon potential map of the Lazio region: A methodological proposal for the European Atlas of Natural Radiation," Journal of Environmental Radioactivity, vol. 166, no. 2, pp. 355-375, 2017.

[2] H. Zeeb, S. Ferid, Handbook on Indoor Radon: a Public Health Perspective. WHO Library, 2009. 
[3] European Commission. "Council Directive 2013/59/Euratom of 5 December 2013 laying down basic safety standards for protection against the dangers arising from exposure to ionising radiation, and repealing Directives 89/618/Euratom, 90/641/Euratom, 96/29/Euratom, 97/43/Euratom and 2003/122/Euratom," Off. J. Eur. Commun, vol. 13, pp. 1-732, 2014.

[4] Health Canada, "Guide for Measurement in Public Buildings (Schools, Hospitals, Care Facilities, Detention centres)," Canadian Minister of Health, 2008.

[5] UNSCEAR (2000) Sources, effects and risk of ionizing radiation. Report to General Assembly with scientific Annexes United Nations.

[6] M. Quarto, M. Pugliese, F. Loffredo, V. Roca. "Indoor radon concentration and gamma dose rate in dwellings of the Province of Naples, South Italy, and estimation of the effective dose to the inhabitants," Radioprotection, vol. 51, no. 1, pp. 31-36, 2016. 